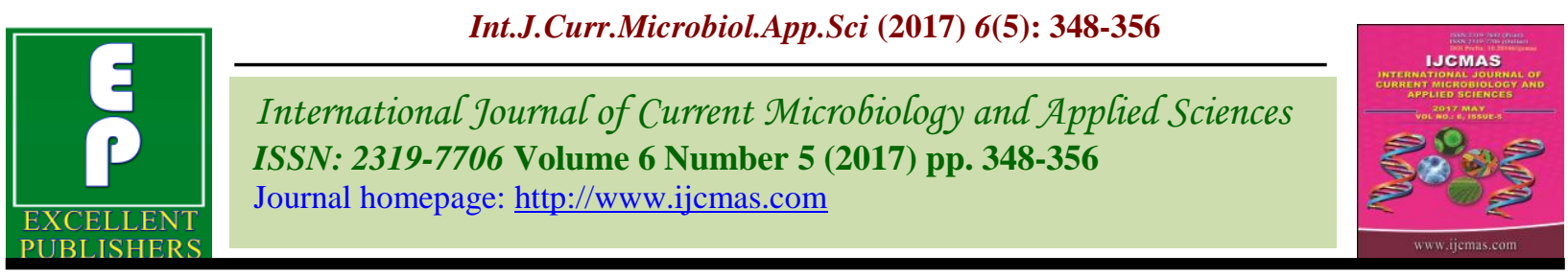

Original Research Article

https://doi.org/10.20546/ijcmas.2017.605.040

\title{
Development and Characterization of Herbal Custard
}

\author{
Chaitali Chakraborty* and Gargi Sharma
}

\begin{abstract}
Department of Food Technology, Gurunanak Institute of Technology, 157/F, Nilgunj Road, Panihati, Sodepur, Kolkata 700114, West Bengal, India

*Corresponding author
\end{abstract}

\begin{tabular}{|c|c|}
\hline & A B S T R A C T \\
\hline $\begin{array}{l}\text { Ke y w o r d s } \\
\text { Pudina, Custard, } \\
\text { Sensory analysis, } \\
\text { Proximate analysis, } \\
\text { Microbiological } \\
\text { analysis, } \\
\text { Rheological } \\
\text { analysis. }\end{array}$ & \multirow{3}{*}{$\begin{array}{l}\text { Herbal Custard is prepared by adding pudina (Mentha spicata) paste into fresh toned milk. } \\
\text { The physicochemical, microbiological, organoleptic and rheological properties were } \\
\text { analyzed to assess the quality of the custard. Physicochemical properties of custard } \\
\text { samples including moisture, ash, fat, protein and carbohydrate content were determined for } \\
\text { all the samples. In this study, many trials have been made with different proportion of } \\
\text { pudina paste i.e. } 1 \%, 2 \% \text {, and } 3 \% \text { using two types of heat treatment i.e. oven and } \\
\text { microwave. Finally the sensory evaluation of all the products were carried out and } \\
\text { according to the panel of judges, overall acceptability of } 2 \% \text { pudina fortified herbal custard } \\
\text { (microwave) was found superior in comparison to others (p<0.01). Total Coliform Count } \\
\text { and total Yeast and Mold Count of different types of herbal custard samples were } \\
\text { determined in } 0,1,3,5 \text { and } 7 \text { days respectively. The shelf stability of herbal custard } \\
\text { gradually increases after } 7 \text { days of storage period in terms of total yeast and mold count } \\
\text { (CFU/g). It was found that no coliforms were present in any samples during storage. The } \\
\text { results of current study demonstrated that the fortification of pudina paste into custard } \\
\text { significantly improve the quality characteristics of the final product. }\end{array}$} \\
\hline Article Info & \\
\hline $\begin{array}{l}\text { Accepted: } \\
\text { 04 April } 2017 \\
\text { Available Online: } \\
10 \text { May } 2017\end{array}$ & \\
\hline
\end{tabular}

\section{Introduction}

In different herbs, a wide variety of active phytochemicals including the flavonoids, terpenoids, lignans, sulfides, polyphenols, carotenoids, coumarins, saponins, plant sterols, curcumins and phthalides have been identified. Mint (Mentha arvensis) contain anti-microbial component volatile oil, carvone, limonene, 1, 8-cineole, trans-carveol, linarin, pulegone, menthol, menthene, menthenone. Fortification of herbs have shown in many food products like in ghee, cream, lassi, sandesh, butter milk, flavored milk, whey beverage etc. Peppermint yields $0.1-1 \%$ of volatile oil composed primarily of menthol (29-48\%), menthone (20-31\%), menthofuran $(6.8 \%)$ and menthyl acetate (3$10 \%$ ). Other pharmacologically active ingredients include bitter substances, caffeic acid, flavonoids (12\%), polymerized polyphenols (19\%), carotenes, tocopherols, betaine, choline and tannins (Sokovic et al., 2009). Measured low to moderate levels of phenolics with antioxidant activity were reported from peppermint (Zheng and Wang, 2001). According to Amr (1990) peppermint contain DPPH (mg AAE/gm) and Phenols (mg GAE/gm) 203.8 and 89.6 respectively. Total polyphenol content of one-milligram pudina extract was equivalent to $500 \mu \mathrm{g}$ of gallic acid. Therefore, this potential 
bioactivity of pudina extract was associated with its high polyphenolic content (Kumar and Chattopadhyay, 2007). Herbs are used in many domains, including medicine, nutrition, flavouring, beverages, dyeing, repellents, fragrances, cosmetics (Djeridane et al., 2006). Many species have been recognized to have medicinal properties and beneficial impact on health, e.g. antioxidant activity, digestive stimulation action, antiinflammatory, antimicrobial, hypolipidemic, antimutagenic effects and anticarcinogenic potential (Aaby et al., 2004). Crude extracts of herbs and spices, and other plant materials rich in phenolics are of increasing interest in the food industry because they retard oxidative degradation of lipids and thereby improve the quality and nutritional value of food.

Custard is a variety of culinary preparations based on a cooked mixture of milk or cream and egg yolk. Depending on how much egg or thickener is used, custard may vary in consistency from a thin pouring sauce (crème anglaise) to a thick pastry cream (French: crème pâtissière). Most common custards are used as desserts or dessert sauces and typically include sugar and vanilla. Custard bases may also be used for quiches and other savory foods. Sometimes flour, corn starch, or gelatin is added as in pastry cream or crème pâtissière. Cooked (set) custard is a weak gel, viscous and thixotropic; while it does become easier to stir the more it is manipulated, it does not, unlike many other thixotropic liquids, recover its lost viscosity over time (Karla et al., 1996).

In this study an attempt has been made to prepare Herbal Custard using pudina paste (@1\%, 2\%, 3\%) by using oven and microwave treatment. The physicochemical, microbiological, organoleptic and rheological properties were compared to assess the quality of the Custard.

\section{Materials and Methods}

\section{Raw material}

Toned milk, sugar, custard powder, pudina leaves were bought from local market of Sodepur.

\section{Preparation of herb paste}

The pudina leaves were washed thoroughly; roots were removed by using a sharp knife and chopped, grinded and stored in refrigerated condition.

\section{Preparation of herbal custard in oven}

Fresh milk was taken and boiled in a saucepan over medium heat. Then custard powder was mixed with small amount of milk (@5\% w/v). The mixture was added in the saucepan and stirred continuously. Sugar was added as milk starts to thicken (@10\% w/v). Then the mixture was boiled and when it reaches its correct consistency it was removed from heat and pudina paste was added (@1\%, $2 \%, 3 \% \mathrm{w} / \mathrm{v})$. Then the product was cooled for half an hour. After cooling the final product was packaged and stored in refrigerator

Preparation of herbal custard in microwave

Fresh milk was taken in a microwave bowl and boiled for $6 \mathrm{~min}$ at $800 \mathrm{~W}$. Then custard powder was mixed with small amount of milk (@5\% w/v). Then the mixture was added in the bowl and stirred for 1min. Sugar was added as milk starts to thicken (@10\% w/v). Then the mixture was boiled for $4 \mathrm{~min}$ at 800 $\mathrm{W}$ and after the end of boiling pudina paste was added (@1\%,2\%,3\%w/v). Then it was mixed well and cooled for half an hour. After cooling the final product was packaged and stored in refrigerator 


\section{Methodology}

The rheological flow properties of shearthinning materials are most commonly described by a two parameter power law model of the form (Jumah et al., 2001).

$\tau=\mathrm{m} \gamma^{\mathrm{n}}$

Where, $\tau$ is the shear stress, $\gamma$ is the shear rate; $m$ is the flow consistency index and $n$ is the flow behavior index. This power-law model is used in this study to describe the behavior of the custard batter. The value of $n$ is less than one for pseudo plastic material.

Total polyphenol content was measured at $765 \mathrm{~nm}$ by Folin-Ciocalteu reagent (McDonald et al., 2001) and expressed in terms of Gallic acid equivalent (GAE).

Custard incorporated with pudina paste (1\%, $2 \%$ and $3 \%$ ) were coded with different numbers and submitted to sensory evaluation by ten member of trained panelists of the department on a 9-point hedonic scale (BIS, 1971). Chemical analysis was done according the method described by AOAC (1999). The data was statistically analyzed using statistical tool ANOVA described by Snedecor and Cochran (1967).

\section{Results and Discussion}

\section{Comparison of sensory quality of different types of herbal custard}

The sensory score and comparison for the parameters of different types of herbal custard (oven) are given in table 1 and figure 1(a). Average overall acceptability score of prepared custard samples were found to be $7.87,8.37$ and 7.75 respectively. Highest score was recorded for sample OC2. The samples had significant influence $(\mathrm{p}<0.01)$ on appearance, color, flavor, body and texture whereas no significant difference was observed $(p>0.01)$ in mouth feelness and overall acceptance.

In case of herbal custard (microwave) samples showed significant influence $(\mathrm{p}<0.01)$ on appearance, color and body and texture and no significant difference was observed ( $>0.01)$ on flavor, mouth feelness and overall acceptability (Table 2 and Fig. 1b). Average overall acceptability score of prepared custard (microwave) samples were found to be 7.2, 8.5, 7.7 and MC2 scored highest overall acceptability among all varieties of custard (both oven and microwave treated).

Semi-solid fat-containing foods such as custards, mayonnaises and sauces are appreciated by consumers because of their creamy mouth feel. This sensory attribute is difficult to describe and is known to be multidimensional. It was demonstrated that creamy mouth feel in custards can be predicted reasonably well from rheological measurements too (Jellema et al., 2005).

\section{Comparison of rheological quality of different types of herbal custard}

Textural characteristics of pudina paste fortified custard samples were analyzed. The results are shown in Fig. 2a-2d by plotting shear stress vs. shear rate and viscosity vs. shear rate. According to the textural analysis, the values of $m$ and $n$ resulting from the fit of the power law model for different samples can be found in table 3 . The values of $n$ in all herbal custard (oven) samples are less than 1 . Therefore it is evident that all samples show pseudo-plastic behavior. The results are comparable with the findings of Jellema et al., (2005) and Dutta et al., (2016).

Whereas the $\mathrm{n}$ value in all types of herbal custard (microwave) samples are greater than 1 which indicates dilatant fluid characteristic. Longrée et al., (1966) reported that fluid 
properties of custard were affected by the types of ingredients used and types of heat treatment given. Systems containing milk, egg and starch were non-Newtonian and time dependent. During shearing viscosity losses, increased as rate of shear increased, and were not recovered upon resting. When the system was overheated, protein-starch aggregates which produced crossed hysteresis loops.

Table.1 Sensory quality of different types of Herbal Custard (Oven) with Anova analysis

\begin{tabular}{|l|c|c|c|c|}
\hline \multicolumn{1}{|c|}{ Parameters } & $\begin{array}{c}\text { OC1 } \\
\text { (avg. } \pm \text { s.d) }\end{array}$ & $\begin{array}{c}\text { OC2 } \\
\text { (avg. } \pm \text { s.d) }\end{array}$ & $\begin{array}{c}\text { OC3 } \\
\text { (avg. } \pm \text { s.d) }\end{array}$ & $\begin{array}{c}\text { Level of } \\
\text { Significance }\end{array}$ \\
\hline Appearance & $7.75 \pm 0.46$ & $7.87 \pm 0.64$ & $7.87 \pm 0.64$ & $* *$ \\
\hline Color & $7.63 \pm 0.52$ & $8.13 \pm 0.64$ & $8.25 \pm 0.46$ & $* *$ \\
\hline flavor & $7.25 \pm 0.88$ & $8.5 \pm 0.53$ & $7.37 \pm 0.74$ & $* *$ \\
\hline Body and texture & $7.75 \pm 0.46$ & $8.5 \pm 0.53$ & $7.37 \pm 0.74$ & $* *$ \\
\hline Mouth feelness & $7.87 \pm 0.64$ & $8.25 \pm 0.70$ & $7.75 \pm 0.88$ & NS \\
\hline Overall acceptance & $7.87 \pm 0.64$ & $8.37 \pm 0.52$ & $7.75 \pm 0.70$ & NS \\
\hline
\end{tabular}

** Significant at $\mathrm{p}<0.01$

$($ avg \pm s.d $)=$ Average \pm Standard Deviation, $\mathrm{n}=10$

$\mathrm{OC} 1=1 \%$ Pudina custard, $\mathrm{OC} 2=2 \%$ Pudina Custard, $\mathrm{OC} 3=3 \%$ Pudina Custard

Table.2 Sensory quality of different types of Herbal Custard (Microwave) with Anova analysis

\begin{tabular}{|l|c|c|c|c|}
\hline \multicolumn{1}{|c|}{ Parameters } & $\begin{array}{c}\text { MC1 } \\
\text { (avg. } \pm \text { s.d) }\end{array}$ & $\begin{array}{c}\text { MC2 } \\
\text { (avg. } \pm \text { s.d) }\end{array}$ & $\begin{array}{c}\text { MC3 } \\
\text { (avg. } \pm \text { sd) }\end{array}$ & $\begin{array}{c}\text { Level of } \\
\text { Significance }\end{array}$ \\
\hline Appearance & $7 \pm 0.48$ & $7 \pm 0.59$ & $7.7 \pm 0.6$ & $* *$ \\
\hline Color & $7 \pm 0.49$ & $8 \pm 0.61$ & $8.2 \pm 0.41$ & $* *$ \\
\hline Flavor & $6.25 \pm 0.78$ & $8.3 \pm 0.5$ & $7.7 \pm 0.68$ & NS \\
\hline Body and texture & $7.7 \pm 0.42$ & $8.1 \pm 0.47$ & $7 \pm 0.72$ & $* *$ \\
\hline Mouth feelness & $7.8 \pm 0.63$ & $8.2 \pm 0.69$ & $7.5 \pm 0.8$ & NS \\
\hline Overall acceptance & $7.2 \pm 0.55$ & $8.5 \pm 0.5$ & $7.7 \pm 0.69$ & NS \\
\hline
\end{tabular}

** Significant at $\mathrm{p}<0.01$

$(\operatorname{avg} \pm$ s.d $)=$ Average \pm Standard Deviation, $\mathrm{n}=10$

$\mathrm{MC} 1=1 \%$ Pudina custard, $\mathrm{MC} 2=2 \%$ Pudina Custard, $\mathrm{MC} 3=3 \%$ Pudina Custard.

Table.3 Fluid flow behavior of different types of herbal custard

\begin{tabular}{|c|c|c|}
\hline Sample & $\boldsymbol{n}$ & $\boldsymbol{m}$ \\
\hline OC1 & 0.33 & 37.67 \\
\hline OC2 & 0.28 & 67.17 \\
\hline OC3 & 0.26 & 86.87 \\
\hline MC1 & 1.702 & 0.6 \\
\hline MC2 & 1.765 & 0.45 \\
\hline MC3 & 1.787 & 0.37 \\
\hline
\end{tabular}

Herbal Custard (Oven): OC1 = 1\% Pudina, OC2 $=2 \%$ Pudina, OC3 = 3\% Pudina.

Herbal Custard (Microwave) MC1 $=1 \%$ Pudina, $\mathrm{MC} 2=2 \%$ Pudina, $\mathrm{MC} 3=3 \%$ Pudina . $m=$ flow consistency index; $n=$ flow behavior index 
Table.4 Chemical analysis of different types of herbal custard

\begin{tabular}{|l|l|l|l|l|l|}
\hline Sample Name & Ash (\%) & $\begin{array}{l}\text { Moisture } \\
(\%)\end{array}$ & Fat (\%) & $\begin{array}{l}\text { Protein } \\
(\%)\end{array}$ & $\begin{array}{l}\text { Carbohydrate } \\
(\%)\end{array}$ \\
\hline Control & 0.9 & 91.4 & 4.5 & 4.4 & 23 \\
\hline OC1 & 0.8 & 94.8 & 4.4 & 4.41 & 22.4 \\
\hline OC2 & 0.6 & 95 & 4.4 & 4.42 & 22.4 \\
\hline OC3 & 0.4 & 95.5 & 4.3 & 4.45 & 22.3 \\
\hline \multicolumn{7}{|l|}{} \\
\hline MC1 & 0.8 & 91.6 & 4.5 & 4.4 & 23 \\
\hline MC2 & 0.6 & 91.8 & 4.4 & 4.4 & 22.5 \\
\hline MC3 & 0.4 & 92 & 4.3 & 4.35 & 22.4 \\
\hline
\end{tabular}

Herbal Custard (Oven): OC1 = 1\% Pudina, OC2 $=2 \%$ Pudina, OC3 = 3\% Pudina.

Herbal Custard (Microwave): $\mathrm{MC} 1=1 \%$ Pudina, $\mathrm{MC} 2=2 \%$ Pudina, $\mathrm{MC} 3=3 \%$ Pudina.

Fig.1 (a) Sensory evaluation of Herbal Custard (Oven); (b) Sensory evaluation of Herbal Custard (Microwave)
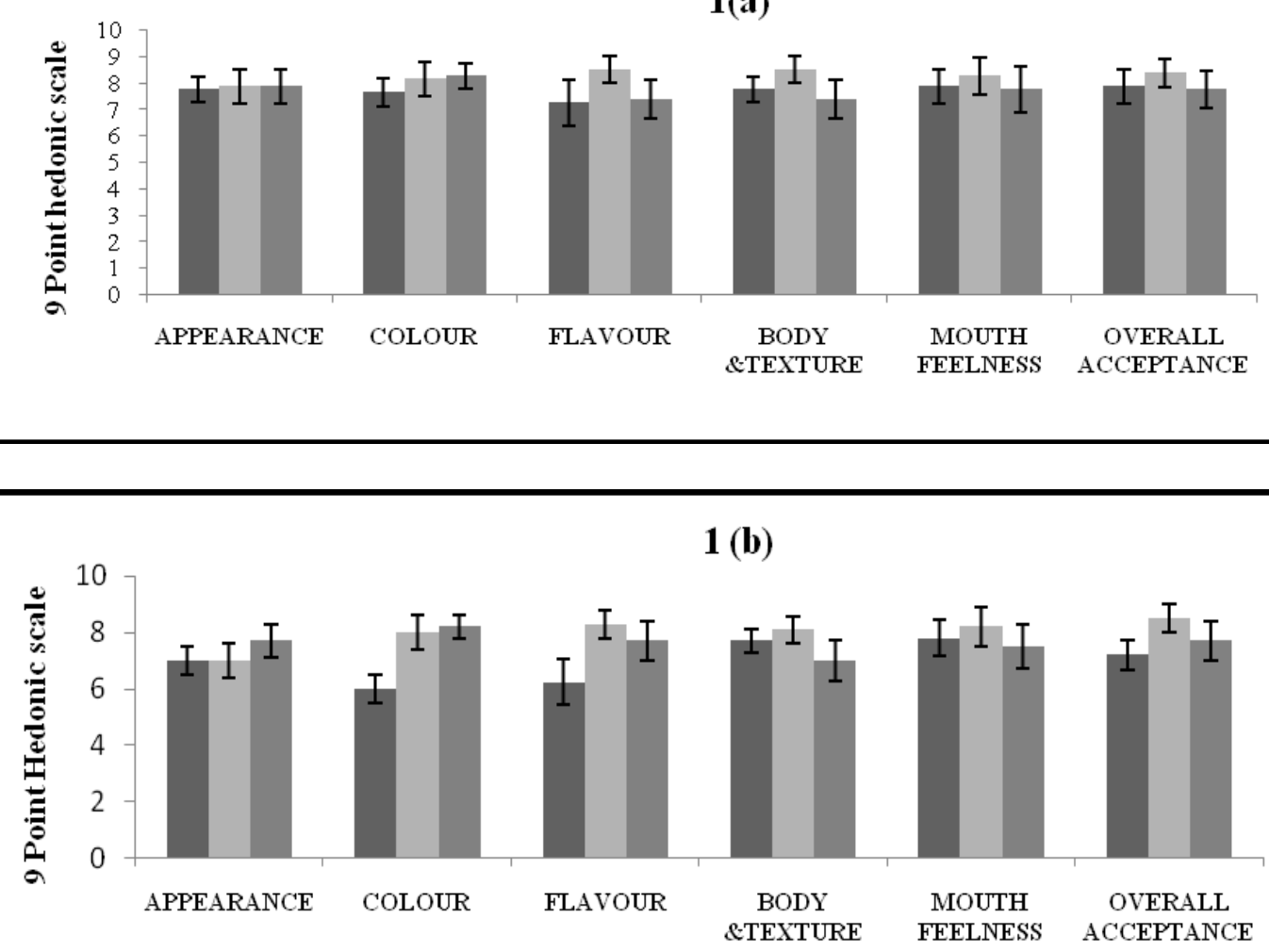

- 1\% pudina

$\llbracket 2 \%$ pudina

$\because 3 \%$ pudina 
Fig.2 Comparative Rheological study of Herbal Custard;

[2(a) and 2(c)= Herbal Custard (Oven); 2(b) and 2(d)= Herbal Custard (Microwave) ]
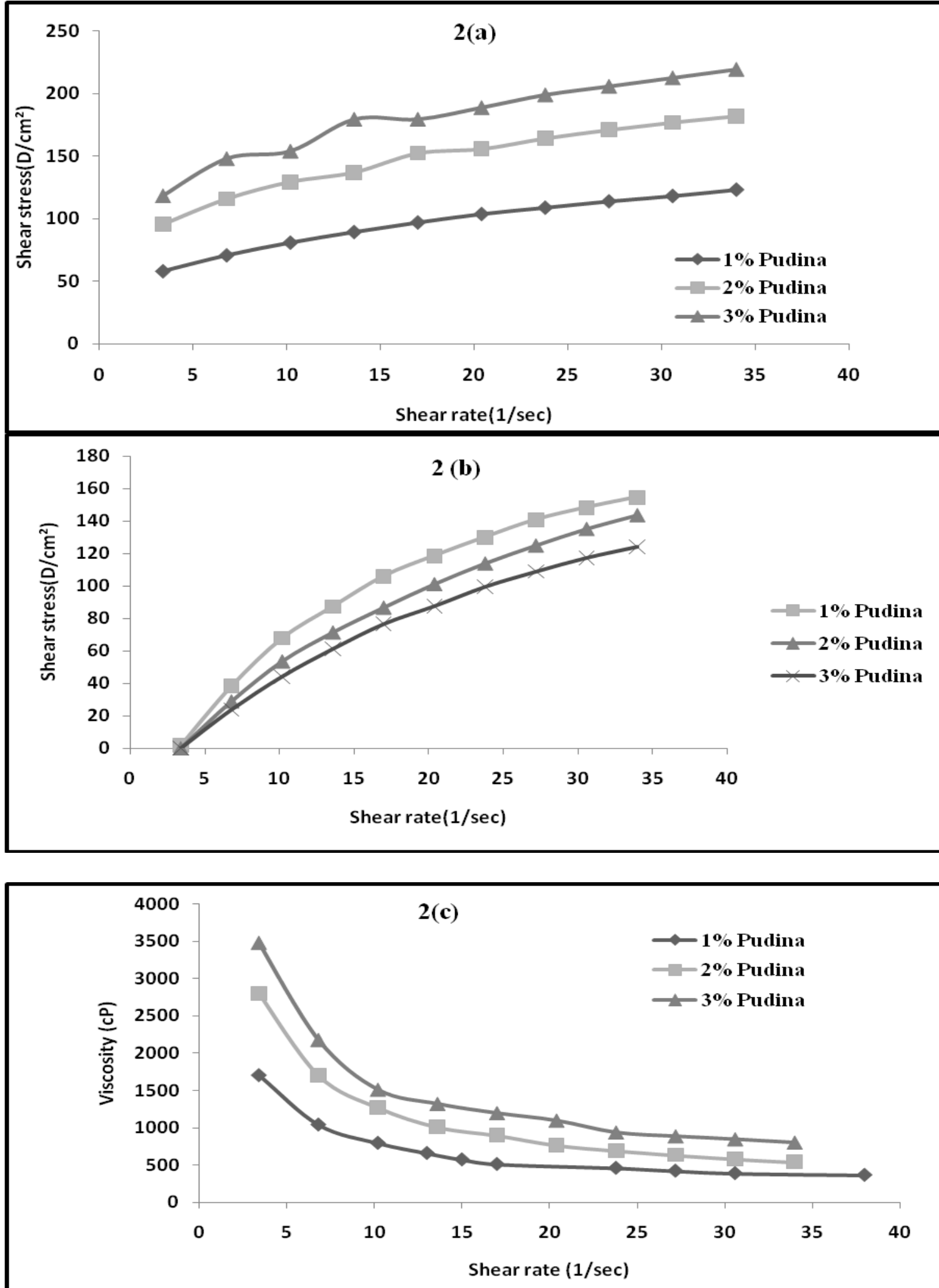


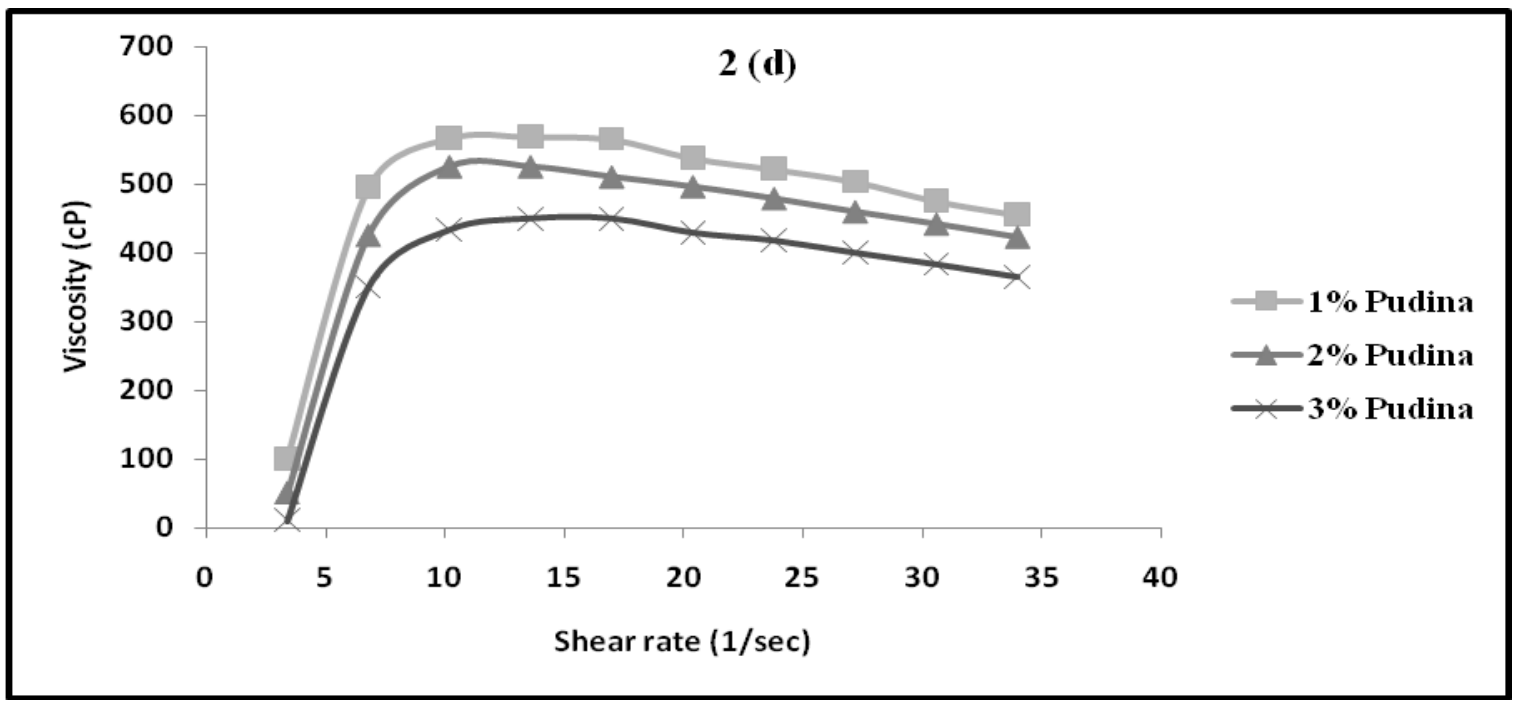

Table.5 Microbial analysis of herbal custard

\begin{tabular}{|l|l|l|l|l|l|l|l|}
\hline $\begin{array}{l}\text { Yeast and } \\
\text { mold count } \\
\text { (CFU/g) }\end{array}$ & Control & OC1 & OC2 & OC3 & MC1 & MC2 & MC3 \\
\hline 0 day & 0 & 0 & 0 & 0 & 0 & 0 & 0 \\
\hline 1 day & 0 & 0 & 0 & 0 & 0 & 0 & 0 \\
\hline 3 day & 0 & 1 & 1 & 1 & 0 & 0 & 0 \\
\hline 5 day & 1 & 2 & 3 & 3 & 1 & 1 & 2 \\
\hline 7 day & 5 & 3 & 4 & 4 & 2 & 2 & 3 \\
\hline Coliform & NIL & NIL & NIL & NIL & NIL & NIL & NIL \\
\hline
\end{tabular}

Herbal Custard (Oven): OC $1=1 \%$ Pudina, OC $2=2 \%$ Pudina, OC $3=3 \%$ Pudina.

Herbal Custard (Microwave): $\mathrm{MC} 1=1 \%$ Pudina, $\mathrm{MC} 2=2 \%$ Pudina, $\mathrm{MC} 3=3 \%$ Pudina

\section{Chemical qualities of different types of herbal custard}

The results of the proximate composition of different types of herbal custard are shown in table 4. Moisture, protein, fat, carbohydrate and ash content were analyzed for their chemical qualities. Sensorically best samples OC2 and MC2 were comparable in respect to ash, fat, protein and carbohydrate content. But OC2 contains higher amount of moisture $(95 \%)$ in respect to MC2 $(92.8 \%)$ may be due to the varying exposure to heat treatment.

\section{Microbiological qualities of different types of herbal custard}

Microbiological characteristics are indicators of safety, quality and shelf life of food sample. Total Coliform Count and Total Yeast and Mold Count of different types of herbal custard samples were determined in 0 , $1,3,5$ and 7 days respectively. Results obtained are shown in table 5. Higher amount of total Yeast and mold count (CFU/g) was recorded in both herbal custard (oven) and herbal custard (microwave) on $5^{\text {th }}$ day of 
storage and the lowest value was recorded for control sample (Table 5). Higher organism count in herbal custard compared to control may be attributed due to the increased level of pudina paste addition in custard. The shelf stability of herbal custard gradually increases after 7 days storage period compared with control in terms of total yeast and mold count $(\mathrm{CFU} / \mathrm{g})$. No coliforms were present in any samples during storage. It is evident that the result occurs due to antimicrobial activity of pudina against enteric pathogens, yeast and mold (Ozcan and Erkmen, 2001).

In conclusion, the new type of pudina paste fortified herbal custard with acceptable physicochemical, organoleptic, microbiological and textural qualities is produced. Both oven and microwave processed herbal custard lies within the acceptable range of all parameters. This new product will help food industries to enrich the production of commercial custard with enhanced health beneficial properties and increased consumer acceptance.

\section{Acknowledgement}

The authors are hereby acknowledging the Honorable Managing Director of JIS Group for financial support and inspiration.

\section{References}

Aaby, K., Hvattum, E., and Skrede, G. 2004. Analysis of flavonoids and other phenolic compounds using highperformance liquid chromatography with coulometric array detection: Relationship to antioxidant activity. $J$ Agri. Food Chem., 52: 4595-4603.

Amr, A.S. 1990. "Role of Some Aromatic Herbs in Extending the Stability of Sheep Ghee During Accelerated Storage", Egypt J. Dairy Sci., Vol. 18(2): 335-344.
AOAC. 1999. Official methods of analysis, 16th edn. Association of Official Analytical Chemists, Washington.

BIS. 1971. IS: 6273. Guide for sensory evaluation of foods. Part II. Methods and evaluation cards. Bureau of Indian Standards. Manak bhavan, New Delhi.

Dutta, P., Adhikari, S., Chakraborty, C., Bandyopadhyay, K., Paul, A., Ray, S. 2016. Development and characterization of curd fortified by pineapple juice. Indian J. Dairy Sci., Vol: 69(5): 524528.

Djeridane, A., Yousfi, M., Nadjemi, B., Boutassouna, D., Stocker, P., Vidal, N. 2006. Antioxidant activity of some Algerian medicinal plants extracts containing phenolic compounds, Food Chem., 97: 654-660.

Jellema, R.H., Janssen, A.M., Terpstra,M.E.J, Wijk, R.A.D., Smilde, A.K. 2005. Relating the sensory sensation 'creamy mouth feel' in custards to rheological measurements, J. Chemometrics, 19(3): 191-200.

Jumah, R.Y., Shaker, R.R., Abu-Jdayil, B. 2001. Effect of milk source on the rheological properties of yogurt during the gelation process, Int. J. Dairy Technol., 54(3): 89-93.

Karla, L., Sharie, B., Paul, B., Joseph, E.N. 1966. Viscous Behavior of Custard Systems. J. Agri. Food Chem., 14(6): 653-659.

Kumar, A., Chattopadhyay, S. 2007. DNA damage protecting activity and antioxidant potential of pudina extract. Food Chem., 100(4): 1377-1384.

Longrée, K., Beaver, S., Buck, P., Nowrey, J.E. 1966. Viscous Behavior of Custard Systems, J. Agric. Food Chem., 14(6): 653-659.

McDonald, S., Prenzler, P.D., Autolovich, M., Robards, K. 2001. Phenolic content and antioxidant activity of olive extracts. Food Chem., 73: 73-84. 
Ozcan, M., Erkmen, O. 2001. Antimicrobial activity of the essential oils of Turkish plant spices, European Food Res. Technol., 212(6): 658-660.

Snedecor, G.W., Cochran, W.G. 1967. Statistical Methods. Oxford and IBH Publ Co, Calcutta, India.

Sokovic, M.D., Vukojevic, J., Marin, P.D., Brkic, D.D., Vajs, V., van Griensven,
L.J. 2009. Chemical composition of essential oils of Thymus and Mentha species and their antifungal activities, Mol., 14(1): 238-249.

Zheng, W., Wang, S.Y. 2001. Antioxidant activity and phenolic compounds in selected herbs, J. Agric. Food Chem., 49(11): 5165-5170.

\section{How to cite this article:}

Chaitali Chakraborty and Gargi Sharma. 2017. Development and Characterization of Herbal Custard. Int.J.Curr.Microbiol.App.Sci. 6(5): 348-356.

doi: http://dx.doi.org/10.20546/ijcmas.2017.605.040 